\title{
ÁCIDO GIBERÉLICO NO RETARDAMENTO DA MATURAÇÃO DE CAgUIS (Diospyrus kaki, L.), CULTIVAR FUYU ${ }^{1}$
}

\author{
Valdecir Carlos FERRI ${ }^{2, *}$, Maria Madalena RINALDI ${ }^{2}$, Jorge Adolfo SILVA ${ }^{3}$, \\ Luciano LUCHETTA ${ }^{2}$, Leonor MARINI ${ }^{2}$, Cesar Valmor ROMBALDI ${ }^{3}$
}

\section{RESUMO}

Objetivou-se estudar o efeito da aplicação de Ácido Giberélico $\left(\mathrm{AG}_{3}\right)$ no retardamento da maturação de caquis da cultivar Fuyu. Adotou-se o delineamento inteiramente casualizado, com quatro repetições. O tratamento foi realizado por pulverização das plantas com 30ppm de $\mathrm{AG}_{3}$. Como tratamento controle pulverizou-se água. A partir da instalação do experimento, na colheita das frutas e a períodos de 7 dias coletaram-se amostras para a avaliação da firmeza de polpa, acidez total titulável, do conteúdo de sólidos solúveis, carotenóides, clorofilas e fenóis, da coloração e da produção de etileno. Os resultados mostraram que o $\mathrm{AG}_{3}$ agiu retardando a maturação em aproximadamente 20 dias, retardando a diminuição da firmeza de polpa, da acidez, do conteúdo de clorofilas e fenóis, e da produção de etileno. Também, agiu retardando o acúmulo de carotenóides e a evolução da coloração externa.

Palavras-chave: frutas; coloração; qualidade; controle da maturação.
\end{abstract}

\section{SUMMARY}

GIBBERELLIC ACID ON RIPENING DELAY OF KAKIS (Diospyrus kaki, L.) CULTIVAR FUYU. This work aimed to evaluate the effect of gibberellic acid $\left(\mathrm{GA}_{3}\right)$, on ripening delay of Kakis cultivar Fuyu. The experiment was designed in completely randomized block with four replications. $\mathrm{GA}_{3}$ was sprayed at $30 \mathrm{ppm}$ and it was sprayed water as a control treatment. Since the installation and in each 7 days, samples were collected for evaluations of pulp firmness, total titrable acidity, total soluble solids, carotenoids, chlorophyll and phenolic contents and ethylene production. The results showed that $\mathrm{GA}_{3}$ retards the ripening at approximately 20 days. It also retarded the decrease of pulp firmness, titrable total acidity, chlorophyll and phenolic contents, ethylene production, the accumulation of carotenoids and the evolution of the external color.

Keywords: fruits; color; quality; ripening control.

\section{1 - INTRODUÇÃO}

Na década de 90 houve um importante incremento na área cultivada e na produção em pomares de caquis, especialmente nos Estados do Rio Grande do Sul e Santa Catarina. Dentre as cultivares recomendadas, a mais difundida foi a Fuyu. Ela produz frutas médio-grandes, não taninosas com boa coloração e sabor.

BEN-ARIE [3] descreve os principais atributos para a comercialização de caquis, da cultivar Fuyu, destacando que, para a colheita, visando a conservação por períodos prolongados, as frutas devem ser colhidas com coloração variando do amarelo-esverdeado ao amareloalaranjado, mais que $60 \mathrm{~N}$ de firmeza de polpa, no mínimo $14^{\circ}$ Brix de sólidos solúveis, e menos do que $3 \mathrm{mg} / \mathrm{kg}$ de fenóis totais. Para frutas destinadas ao consumo imediato e/ou armazenamento por curtos períodos, pode-se retardar a colheita, colhendo-se as frutas com coloração amarelo-avermelhado ou avermelhada, e com menor firmeza de polpa. Ressalta, no entanto, que para esta cultivar há necessidade de uma firmeza de polpa mínima de $20 \mathrm{~N}$.

No Rio Grande do Sul e Santa Catarina, a colheita desta cultivar coincide com a de outras regiões produtoras, especialmente o Estado de São Paulo. Por isto,

\footnotetext{
1. Recebido para publicação em 21/02/2001. Aceito para publicação em 22/12/2003 (000597).

2. FAEM/UFPel. Rua Gonçalves Chaves, 805/203, CEP-96.015-560 Pelotas RS

3. DCTA/FAEM/UFPel

* A quem a correspondência deve ser enviada.
}

há necessidade de adoção de medidas de manejo précolheita e de pós-colheita para controlar a maturação e/ou a conservabilidade para prolongar o período de oferta e garantir melhores preços ao produtor.

Uma das alternativas consiste no emprego de produtos, em pré-colheita, capazes de retardar a velocidade da maturação, retardando a colheita. Neste particular são citados principalmente inibidores da síntese e/ou da ação do etileno, como aminoethoxivinilglicina, narbornadiene, tiosulfato de prata e 1-metilciclopropano $[1,7,17]$. A maioria destes produtos foi testada em outras espécies e os resultados foram variados, dependendo das características varietais e condições edafoclimáticas [1].

Outros autores $[2,5,8,9,10]$ têm recomendado o emprego de giberelinas, como o $\mathrm{AG}_{3}$, na concentração de 30ppm [9,14], no controle da maturação de frutas. Segundo estes autores, o $\mathrm{AG}_{3}$ age reduzindo a velocidade de evolução da coloração das frutas retardando a colheita. $\mathrm{O} \mathrm{AG}_{3}$ [13] atua inibindo a ação de clorofilases e inibindo a produção de etileno. Porém, não demonstram o mecanismo de ação e como este fitoregulador age nestas vias bioquímicas. Em caquis, os resultados são escassos, mas apontam para um bom potencial, principalmente reduzindo distúrbios fisiológicos na póscolheita [4, 14]. Entretanto, relatos feitos por produtores do Rio Grande do Sul, Santa Catarina e São Paulo indicam que a aplicação de $\mathrm{AG}_{3}$ permite retardar a maturação (comunicação pessoal).

Dentro deste contexto, estudou-se o efeito do $\mathrm{AG}_{3}$ aplicado na pré-colheita sobre a evolução da maturação de caquis da cultivar Fuyu. 


\section{2 - MATERIAL E MÉTODOS}

O experimento foi realizado com caquis, cultivar Fuyu, na safra 1996/1997, na Empresa Balarin \& Cia Ltda., de Caxias do Sul - RS.

Como os dados disponiveis na Empresa indicavam que a data média de colheita dos caquis, em anos anteriores, situava-se no período de 20 e 30 de abril, procedeu-se a aplicação de ácido giberélico $\left(\mathrm{AG}_{3}\right)$, na concentração de 30ppm, no dia 22 de março, correspondendo, aproximadamente, a 30 dias antes da colheita.

A aplicação de $\mathrm{AG}_{3}$ foi realizada por pulverização de cobertura da parte aérea das plantas, até gotejamento, utilizando-se o produto comercial Progib ${ }^{\circledR}$, que contém $10 \%$ de $\mathrm{AG}_{3}$. Como tratamento controle, pulverizaramse as plantas com água.

O delineamento experimental adotado foi o inteiramente casualizado. Cada unidade experimental foi constituída de 25 plantas e realizaram-se quatro repetições. Para cada avaliação coletaram-se 4 frutas por planta, na porção mediana externa da copa, posições norte, sul, leste e oeste.

Para a monitorização da evolução da maturação das frutas que permaneciam nas plantas, determinaramse, na instalação do experimento em 22 de março, e a cada 7 dias, até 24 de maio, a firmeza de polpa, o teor de sólidos solúveis totais, a acidez total titulável, a coloração externa, o conteúdo de clorofilas, carotenóides e fenóis, e a produção de etileno.

A firmeza de polpa (FP) foi determinada com o auxílio de penetrômetro manual, com ponteira de $8 \mathrm{~mm}$ de diâmetro, e os resultados expressos em Newton (N).

O teor de sólidos solúveis totais (SST) foi determinado por refratometria, e os resultados expressos em ${ }^{\circ}$ Brix.

A acidez total titulável (ATT) foi determinada por titulometria de neutralização, e os resultados expressos em cmol.L-1.

A coloração externa foi avaliada visualmente adotando-se uma escala de notas de coloração variando de: 1-verde; 2-verde-amarelado; 3-amarelo-esverdeado; 4-amarelo-alaranjado; 5-amarelo-avermelhado; 6-vermelho; 7-vermelho intenso.

Os conteúdos de clorofilas e de carotenóides foram determinados através da metodologia descrita em INSTITUTO ADOLFO LUTZ [11], com resultados expressos em mg. $\mathrm{kg}^{-1}$ de peso fresco das frutas.

Conteúdos de fenóis: seguiu-se a metodologia descrita por $\mathrm{PECH}$ et al. [13], com resultados expressos em mg. $\mathrm{kg}^{-1}$ de fruta.

O etileno foi determinado por cromatografia em fase gasosa, utilizando um cromatógrafo a gás $\mathrm{N}$, He, marca $\operatorname{Varian}^{\circledR}$, modelo 3300, equipado com uma coluna de aço inox 1/8", preparado com Porapak ${ }^{\circledR} \mathrm{N}$, e um detetor de ionização de chama. As temperaturas da câmara de injeção, coluna $(5 \mathrm{~cm})$ e do detector foram de $80^{\circ} \mathrm{C}, 90^{\circ} \mathrm{C} \mathrm{e}$ $200^{\circ} \mathrm{C}$, respectivamente. Utilizou-se como padrão, uma solução de etileno a 10ppm. Para a determinação da produção de etileno duas frutas foram condicionadas em frascos hermeticamente fechados, durante uma hora a $25^{\circ} \mathrm{C}$. Passado esse período coletou-se, com auxílio de seringas split less hipodérmicas, $1 \mathrm{~mL}$ da atmosfera gasosa. A quantificação foi feita correlacionando-se a média das alturas dos picos relativos a cada amostra, com a média das alturas dos picos obtidos da solução padrão de etileno.

Para a comparação de médias dos resultados utilizou-se o teste de Duncan a $5 \%$ de probabilidade e para o estudo das variações durante a maturação adotou-se a regressão polinomial.

\section{3 - RESULTADOS E DISCUSSÃO}

De maneira geral pode-se observar que o tratamento com ácido giberélico influenciou significativamente as variações na firmeza de polpa, no conteúdo de sólidos solúveis totais, clorofilas, carotenóides e fenóis, na acidez total titulável e produção de etileno.

As variações de firmeza de polpa foram significativas entre os tratamentos testados e durante o período de avaliação. Assim, houve uma perda linear da firmeza de polpa passando de $147 \mathrm{~N}$ em 22 de março, para $62 \mathrm{~N}$ em 24 de maio, nas frutas de plantas tratadas com $\mathrm{AG}_{3}$. Neste mesmo período, em plantas não tratadas com $\mathrm{AG}_{3}$, a redução de firmeza de polpa foi mais acentuada, atingindo $3 \mathrm{~N}$ em 24 de maio (Figura 1).

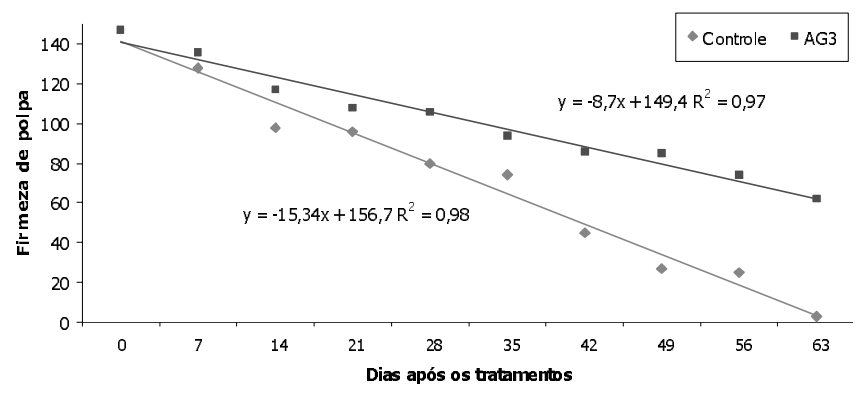

FIGURA 1. Firmeza de polpa durante a maturação de caquis cultivar Fuyu.

Para caquis Fuyu destinados ao armazenamento e/ou para a comercialização em condições ambientais não controladas, recomenda-se a colheita das frutas com firmeza de polpa entre 60 e $80 \mathrm{~N}$. Para consumo imediato ou em curtos períodos, inferiores a 7 dias, a colheita pode ser retardada, aguardando que as frutas atinjam valores de firmeza de polpa entre 40 e $60 \mathrm{~N}$. Destaca-se, no entanto, que a firmeza de polpa mínima para a boa aceitabilidade desta cultivar situa-se acima de 20N [3, 16]. Baseando-se nestas considerações pode-se verificar que a aplicação de $\mathrm{AG}_{3}$ permite retardar em aproximadamente 20 dias a colheita desta fruta, já que em 26 de abril as frutas controle apresentavam $74 \mathrm{~N}$ e as tratadas com $\mathrm{AG}_{3}$ só apresentaram este valor em 15 de maio. O efeito positivo da aplicação do $\mathrm{AG}_{3}$ sobre a preservação de melhores valores de firmeza de polpa deve-se, provavelmente, à diminuição da atividade metabólica na parede [13], especialmente pela 
redução da produção de etileno em frutas tratadas com esta giberelina.

No que se refere ao conteúdo de sólidos solúveis totais (SST), observou-se um incremento durante a maturação, mais acentuado em caquis não tratados com $\mathrm{AG}_{3}$. Em média, em 22 de março, as frutas apresentavam $8^{\circ}$ Brix, passando, para 16,5 e $17,5^{\circ}$ Brix em 24 de maio, respectivamente, em caquis tratados com $\mathrm{AG}_{3} \mathrm{e}$ não tratados (Figura 2).

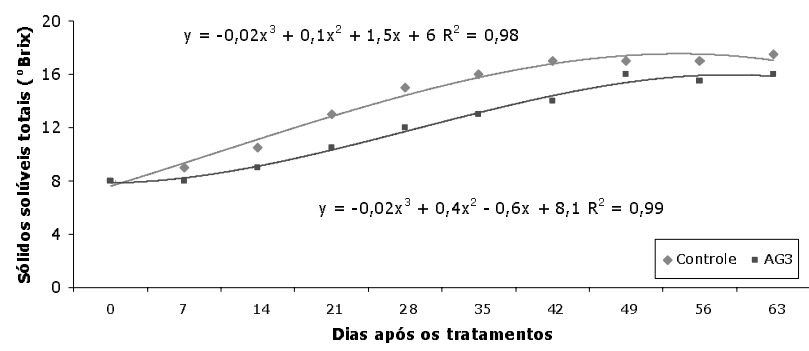

FIGURA 2. Sólidos Solúveis Totais durante a maturação de caquis cultivar Fuyu.

Baseando-se nas variações de firmeza de polpa ( $F i-$ gura 1), que apontam para a colheita das frutas do tratamento controle em 26 de abril e do tratamento com $\mathrm{AG}_{3}$ em 15 de maio, o conteúdo de SST nestas mesmas datas, foi, respectivamente de $15,5^{\circ}$ Brix e $16,0^{\circ}$ Brix. Estes valores estão acima dos limites considerados adequados ( $14^{\circ}$ Brix) para esta cultivar.

No que se refere à acidez total titulável (ATT) observou-se um decréscimo linear para as frutas tratadas com $\mathrm{AG}_{3}$ (Figura 3). Este é o comportamento normal para a maioria das frutas, excetuando-se as de caroço, como pêssegos, ameixas e nectarinas que, em estádios mais avançados de maturação, detecta-se um incremento na ATT correlacionando-se com a geração de radicais ácidos na parede celular [4]. Isto foi observado em caquis do tratamento controle. Houve uma redução inicial de ATT, até 26 de abril, após o qual, observou-se acréscimos.

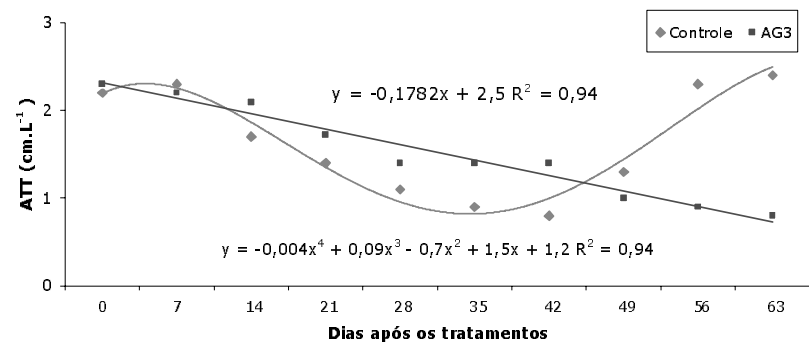

FIGURA 3. Acidez Total Titulável (ATT) durante a maturação de caquis cultivar Fuyu.

O conteúdo de fenóis também apresentou reduções significativas durante a maturação, porém mais acentuadas em frutas não tratadas com $\mathrm{AG}_{3}$ (Figura 4). Embora as frutas da cultivar Fuyu sejam enquadradas como caquis do grupo não taninoso, o conteúdo de fenóis é relativamente elevado se comparado a outras espécies [5, 12]. De maneira geral, os caquis devem apresentar, para o consumo, teores de fenóis in- ferior a 3mg.kg-1 [12]. Baseando-se nesta informação, verifica-se que as frutas colhidas de plantas tratadas com $\mathrm{AG}_{3}$ atendem esta condição a partir de 12 de abril, enquanto àquelas tratadas com $\mathrm{AG}_{3}$, isto só ocorre a partir de 05 de maio.

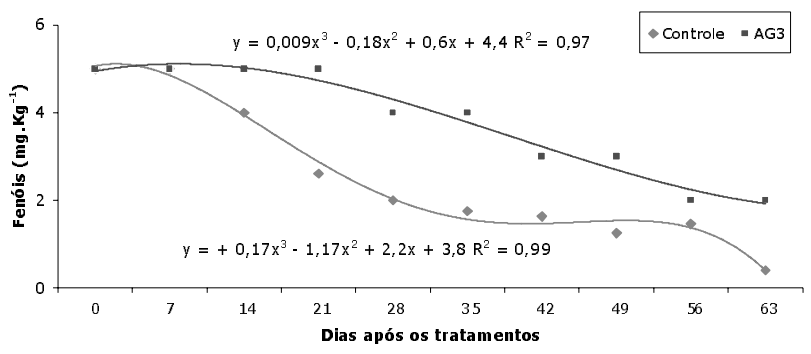

FIGURA 4. Conteúdo de Fenóis durante a maturação de caquis cultivar Fuyu.

A coloração da epiderme (Figura 5), avaliada visualmente, também apresentou-se significativamente afetada pela aplicação de $\mathrm{AG}_{3}$. Os caquis não tratados com $\mathrm{AG}_{3}$ atingiram a nota 5 - coloração amarelo-avermelhado, citada por BEN-ARIE [3] como adequada para o consumo, em 26 de abril, enquanto aqueles de plantas tratadas, ainda apresentavam-se com a nota 2 - verde-amarelado. Estes só adquiriram a coloração da epiderme amarelo-avermelhado a partir de 15 de maio. Este comportamento é fundamentado nas variações nos conteúdos de carotenóides (Figura 6) e de clorofilas (Figura 7), já que a aplicação de $\mathrm{AG}_{3}$ reduziu o acúmulo de carotenóides e a degradação de clorofilas.

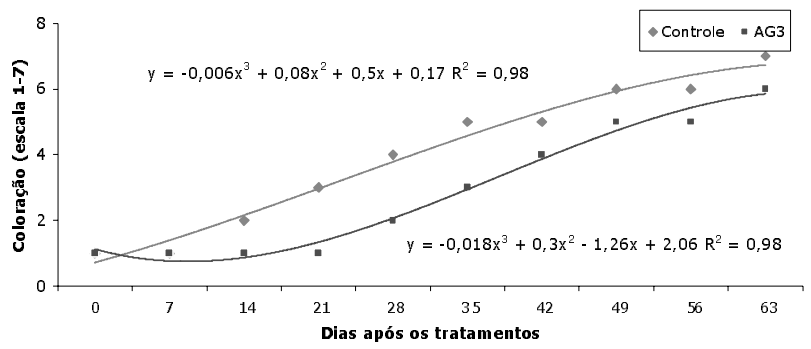

FIGURA 5. Evolução da coloração durante a maturação de caquis cultivar Fuyu.

Semelhantemente as demais variáveis estudadas, o $\mathrm{AG}_{3}$ também teve efeito significativo sobre a produção de etileno (Figura 8). Além da diminuição da produção de etileno, o $\mathrm{AG}_{3}$ retardou o início da crise climatérica em aproximadamente 15 dias. Em frutas sensiveis ao etileno [13], como é o caso de caquis, o controle do início e da intensidade de síntese deste hormônio pode ser fator regulador da maturação.

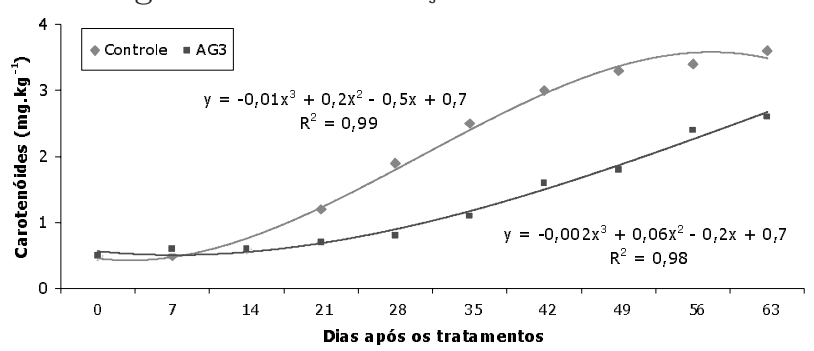

FIGURA 6. Conteúdo de carotenóides durante a maturação de caquis cultivar Fuyu. 


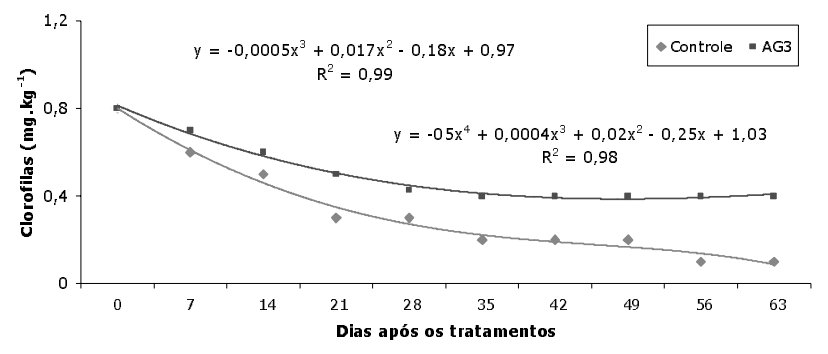

FIGURA 7. Conteúdo de clorofilas durante a maturação de caquis cultivar Fuyu.

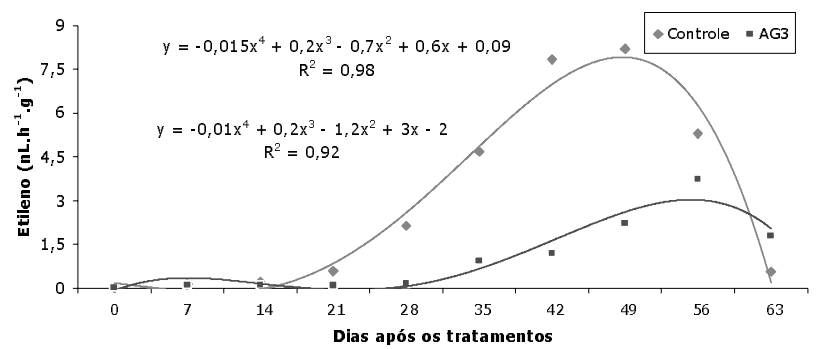

FIGURA 8. Produção de etileno durante a maturação de caquis cultivar Fuyu.

Neste trabalho, o atraso observado para a ocorrência da crise climatérica corresponde à decalagem para a ocorrência das demais transformações. Porém, pela metodologia empregada, não se pode verificar se o etileno atuou como causa ou conseqüência das alterações.

Adotando-se os valores-base [3], pode-se verificar que a colheita dos caquis tratados com $\mathrm{AG}_{3}$ deve ser realizada em torno do dia 15 de maio. Já para as frutas de plantas não tratadas com $\mathrm{AG}_{3}$, a data de colheita deve ser antecipada para 26 de abril. Nestas condições, as frutas apresentam-se amarelo-avermelhado, com firmeza de polpa em torno de $70 \mathrm{~N}$, mais do que $15^{\circ} \mathrm{Brix}$ e com um conteúdo de fenóis médio de $2 \mathrm{mg} / \mathrm{kg}$.

Este retardamento de colheita, de aproximadamente 20 dias, pode ser ainda mais prolongado se as frutas forem destinadas ao consumo/comercialização imediata. Mesmo com a colheita em 24 de maio, o que representa um retardo de aproximadamente um mês, a firmeza de polpa ainda é elevada (62N) e as demais variáveis estão perfeitamente de acordo com as condições para a comercialização. Além disto, as frutas apresentam-se com aspecto mais atraente, sobretudo pela coloração avermelhada mais intensa.

Para frutas de plantas não tratadas com $\mathrm{AG}_{3}$, se a colheita for realizada após 26 de abril, a comercialização deverá ser realizada em curtos períodos, pois observa-se uma significativa perda de firmeza, comprometendo a qualidade das mesmas.

A observação conjunta destes dados indica que a aplicação de $\mathrm{AG}_{3}$ constitui-se, também, numa alternativa para o escalonamento de colheita dos caquis, além de prolongar a oferta. A aplicação deste fitoregulador resultou um ganho no período de oferta de caquis semelhante ao proporcionado pelo armazenamento refrigerado a $0 \pm 0,5^{\circ} \mathrm{C}$, que é de aproximadamente 30 dias
[5, 6, 15]. Além disto, o benefício da aplicação de $\mathrm{AG}_{3}$ pode ser ampliado, pois após a colheita, as frutas poderão ser conservadas por um período adicional, sob refrigeração. Há necessidade, no entanto, de verificar o efeito do $\mathrm{AG}_{3}$ no potencial de conservação após a colheita. Também, sugere-se, na continuidade dos trabalhos, avaliar o efeito do uso de $\mathrm{AG}_{3}$ na produtividade do pomar no ano da aplicação e em safras sucessivas.

\section{4 - CONCLUSÕES}

A aplicação de $\mathrm{AG}_{3}$ permite retardar a maturação, decalando a colheita de caquis, da cultivar Fuyu, em até 20 dias.

\section{5 - REFERÊNCIAS BIBLIOGRÁFICAS}

[1] AUTIO, W.R.; BRAMLAGE, W.J. Effects of AVG on ripening and storage of apples. Journal American Socciety for Horticultural Science, Alexandria, v. 107, n. 6, p. 1074-1077, 1982.

[2] BEN-AIRIE, R.; BAZAK, H.; BLUMENFELD, A. Gibberellin delays harvest and prolongs life of persimmon fruits. Acta Horticulturae, Wageningen, v. 179, p. 807-813, 1986.

[3] BEN-ARIE, R. Comercial quality of "Fuyu" persimmon. Postharvest, Amsterdam, v. 14, n. 3, p. 311-317, 1995.

[4] BEN-ARIE, R.; SAKS, Y.; SONEGO, L.; FRANK, A. Cell wall metabolism in gibberellin-treated persimmon fruits. Plant Growth Regulation, Amsterdam, n. 19, p. 2533, 1996.

[5] BEN-ARIE, R.; ZUTKHI, Y. Extending the storage life of "Fuyu" persimmon by modified-atmosphere packaging. HortScience, Amsterdam, v. 27, n. 7, p. 811-813, 1992.

[6] BRACKMANN, A., MAZARO, S.M.; SAQUET, A.A. Frigoconservação de caquis (Diospyros kaki, L.) das cultivares Fuyu e Rama Forte. Ciência Rural, Santa Maria, v. 27, n. 4, p. 561-565, 1997.

[7] BYERS, R.E. Peach and nectarine fruit softening following Aminoethoxy-vinylglycine sprays and dips. HortScience, Alexandria, v. 32, n. 1, p. 86-88, 1997.

[8] GROSS, J.; BAZAK, H.; BLUMENFELD, A.; BEN-ARIE, R. Changes in chlorophyll and carotenoid pigments in the peel of "Triumph" persimmon (Diopyros kaki, L.) induced by pre-harvest gibberellin $\left(\mathrm{GA}_{3}\right)$ treatment. Scientia Horticulturae, Amsterdam, v. 24, p. 305-314, 1984.

[9] GROSS, K.C. A rapid and sensitive spectrophotometric method for assaying polygalacturonase using 2cyanoacetamide. HortScience, Alexandria, v. 17, p. 933-934, 1982.

[10] INSTITUTO ADOLFO LUTZ. Normas analíticas do Instituto Adolf Lutz: Métodos químicos para análise de alimentos. São Paulo: $3^{\circ}$ ed. 533p. 1985.

[11] KANG, I.K; SUH, S.G.; GROSS, K.C.; BYUN, J.K. Nterminal amino acid sequence of persimmon fruit bgalactosidase. Plant Physiology, Rockville, n. 105, p. 975-979, 1994.

[12] OOGAKI, C.; WANG, H.G.; GEMMA, H. Physiologycal and biochemical characteristics and keeping qualities of temperate fruits during chilled storage. Acta Horticulturae, Wageningen, v. 379, p. 337-344, 1990.

[13] PECH, J.C.; LATCHÉ, A.; BALAGUÉ, C.; BOUZAYEN, M.; LELIẼVRE, J.M. Postharvest physiology of climateric 
fruits: recent development in the biosyntesis and action of ethylene. Sciencia Alim, Toulous, v. 14, p. 3-14, 1994.

[14] PEREZ, A.; BEN-ARIE, R.; DINNOR, A.; GENIZI, A.; PRUSKY, D. Prevention of black spot disease in persimmon fruit by gibberellic acid and iprodione treatments. Phytopathology, St. Paul, v. 85, n. 2, p. 221-225, 1995.

[15] RINALDI, M.M.; FERRI, V.C.; ROMBALDI, C.V. Frigoconservação de caquis (Diospyros kaki, L.) cv. Fuyu, em atmosfera modificada. In: Congresso Brasileiro de
Ciência e tecnologia de Alimentos, XVI, 1998, Rio de Janeiro, RJ. Anais... Rio de Janeiro: S.B.C.T.A. - Universidade Federal do Rio de Janeiro. v. 2. p. 415-420, 1998.

[16] ROMBALDI, C. V. Armazenamento de caqui. Jornal da Fruta, Lages, n. 232, p. 4, 1999.

[17] WILLIAMS, W.M. Retention of fruit firmness and increase in vegetative growth and fruit set of apples with Aminoethoxyvinylglycine.

HortScience, Alexandria, v. 15, n. 1, p. 76-77, 1980. 